\title{
内蒙古西部自然植被的物种多样性及其影响因素
}

\author{
杨崇曜 ${ }^{1}$ 李恩贵 1 陈慧颖 ${ }^{1} \quad$ 张景慧 $^{2} \quad$ 黄永梅 $^{1 *}$ \\ 1 (地表过程与资源生态国家重点实验室, 北京师范大学地理科学学部, 北京 100875) \\ 2 (内蒙古大学生态与环境学院, 呼和浩特 010021)
}

\begin{abstract}
摘要: 为深入认识干旱半干旱地区生物多样性的形成机制, 本文基于2012-2015年对内蒙古西部的温带草原、温带 灌丛、草甸和荒漠4种植被型调查获取的 74 个样地数据, 对比了不同植被型的物种多样性差异, 分析了不同环境因 子对内蒙古西部自然植被物种多样性的影响。结果表明: (1)综合Simpson指数、Patrick丰富度指数、Shannon-Wiener 指数和Pielou均匀度指数分析, 内蒙古西部温带草原和草甸的物种多样性相近, 在4种植被型中最高, 荒漠的物种 多样性最低。(2) Pearson相关分析结果表明, 气候因子中, 年均温、年降水量、潜在蒸散量和最冷月均温对群落物 种多样性均具有显著影响, 其中Patrick丰富度指数、Shannon-Wiener指数、Simpson指数均与年均温、潜在蒸散量 呈显著的负相关关系, 前两者还与年降水量呈显著的正相关关系, 各气候因子对Pielou均匀度指数的影响均不显 著。(3)土壤化学性质中的土壤 $\mathrm{pH}$ 值、有机碳和全氮含量均对物种多样性有显著影响。(4)多元回归分析发现, 潜在 蒸散量和土壤有机碳含量是影响Patrick丰富度指数和Shannon-Wiener指数的主导因子, 而Simpson指数的主导因 子仅为土壤有机碳含量, Pielou均匀度指数的主导因子为土壤全氮含量。
\end{abstract}

关键词：植被型；物种多样性；气候因子；土壤化学性质；内蒙古西部

\section{Biodiversity of natural vegetation and influencing factors in western In- ner Mongolia}

\author{
Chongyao Yang ${ }^{1}$, Engui $\mathrm{Li}^{1}$, Huiying Chen ${ }^{1}$, Jinghui Zhang ${ }^{2}$, Yongmei Huang ${ }^{1 *}$ \\ 1 State Key Laboratory of Earth Surface Processes and Resource Ecology, Faculty of Geographical Science, Beijing \\ Normal University, Beijing 100875 \\ 2 School of Ecology and Environment, Inner Mongolia University, Hohhot 010021
}

\begin{abstract}
To determine biodiversity, 74 plant community plots were surveyed in western Inner Mongolia between 2012 and 2014. These samples were divided into four vegetation types, including temperate steppe, temperate shrub, meadow, and desert. Four biodiversity indices (Patrick index, Simpson index, Shannon-Wiener index and Pielou index) were calculated to show biodiversity differences among the four vegetation types. Climate and soil data were also collected over the course of the survey. Pearson correlation analysis was conducted to reveal the relationship between biodiversity and environmental factors and stepwise regression analysis was used to determine dominant environmental factors. Results indicated that: (1) In western Inner Mongolia, biodiversity indices were different among the four vegetation types. Temperate steppe and meadow had similar values for biodiversity indices, and were also the highest amongst all vegetation types, while the lowest biodiversity was found in the desert. (2) Pearson correlation analysis showed that the Patrick index, Shannon-Wiener index, and Simpson index were all negatively and linearly correlated with mean annual temperature and potential evapotranspiration. (3) Among all chemical properties of the soil, $\mathrm{pH}$, organic carbon and total nitrogen all influenced biodiversity indices. (4) Stepwise regression analysis showed that potential evapotranspiration and soil organic carbon were the most influential factors affecting the Patrick index and Shannon-Wiener index. The only dominant factor for the Simpson index was soil organic carbon while soil total nitrogen was most important factor for the Pielou index.
\end{abstract}

收稿日期: 2017-05-12; 接受日期: 2017-12-01

基金项目：科技基础性工作专项“华北地区自然植物群落资源综合考察” (2011FY110300)

* 通讯作者 Author for correspondence. E-mail: ymhuang@bnu.edu.cn 
Key words: vegetation types; biodiversity; meteorological factors; soil chemical properties; western Inner Mongolia

物种组成及其多样性是群落最基本的特征，是 形成群落的基础(王春玲等, 2005)。物种多样性对于 维持群落功能, 特别是环境条件多变的群落的功能 具有至关重要的意义(Loreau et al, 2001)。物种多样 性的变化与生境紧密相关(汪殿蓓等, 2001), 生物多 样性沿环境梯度的变化规律已成为生物多样性研 究的一个重要议题(唐志尧和方精云, 2004), 了解影 响植物群落物种多样性的关键因素及其相互关系 对预测群落多样性的动态变化有着重要意义。影响 植物群落物种多样性的因素可分为环境因子和生 物因子两类(汪殿蓓等，2001)。环境因子中, 经度 (Qian et al, 1998; 马斌等, 2008)、纬度(贺金生和陈 伟烈, 1997)、海拔(唐志尧和方精云, 2004; 王长庭 等, 2004; 朱源等, 2007; 徐远杰等, 2010)、气候(冯 建孟, 2008; Bellard et al, 2012)、地质地貌(郑江坤等, 2009)、土壤的物理化学性质 (郑敬刚等, 2009; Sander \& Wardell-Johnson, 2011)等都会对群落的物 种多样性产生影响。生物因子尤其是人为活动干扰 对植物群落物种多样性的改变影响也较大(汪殿蓓 等, 2001)。在大尺度范围, 群落物种多样性主要受 纬度和海拔影响, 一般认为物种多样性随纬度增加 而下降(Brown \& Lomolino, 1998), 而随海拔梯度的 变化有多种形式, 最常见的为负相关和中间高度 “膨胀现象” (沙威等, 2016)两种。而在区域尺度上, 地形、气候、土壤则成为主要影响因素, 这3种要素 的不同组合产生了复杂的群落物种多样性格局 (Phillips et al, 2003)。

内蒙古西部横跨半干旱、干旱两个气候带, 植 被和土壤都具有明显的地带性分布差异, 植物群落 类型丰富(冯学武等, 2003)。作为我国西北干旱区的 重要组成部分, 该地区已有大量研究。如孙小丽等 (2015)对荒漠草原物种多样性和生产力的研究, 代 爽等(2013)探讨了灌木群落物种丰富度与气候的关 系, 张静妮等(2010)通过对贝加尔针茅(Stipa baicalensis)草原的研究, 阐述了土壤化学性质对草地 群落植物组分、结构和多样性格局的影响。但这些 研究多集中在单一群落类型(周志宇等, 2009; 张静 妮等, 2010; 代爽等, 2013; 孙小丽等, 2015), 而对
区域尺度的群落物种多样性特征及其空间分布格 局的研究较少。在生物多样性形成机制的环境解释 方面, 有很多研究只针对气候或土壤单一因子对物 种多样性的影响(刘先华等, 1998; 白永飞等, 2000; 左小安等, 2007; 宋创业等, 2008), 将气候和土壤等 环境因子相结合的综合分析研究尚不多见, 这不利 于对干旱半干旱地区生物多样性形成机制的深入 认识。本文在华北植物群落综合调查项目的支持下, 在2012-2015年通过实地调查获取了内蒙古西部4 个植被类型共 74 个样地的数据, 分析了该区自然植 被的物种多样性特征及其空间分布格局。在此基础 上, 结合降水、气温、土壤等环境数据, 进一步探 讨了干旱半干旱地区自然环境因素对物种多样性 的影响。

\section{1 材料与方法}

\section{1 研究区概况}

内蒙古西部包括乌兰察布、呼和浩特、包头、 鄂尔多斯、巴彦淖尔、乌海和阿拉善7个盟市, 地理 坐标为 $37^{\circ} 30^{\prime}-42^{\circ} 47^{\prime} \mathrm{N}, 95^{\circ} 05^{\prime}-114^{\circ} 49^{\prime} \mathrm{E}$ 。该区以高 原地貌为主，平均海拔超过 $1,000 \mathrm{~m}$ 。气候以温带大 陆性季风气候为主, 年均温约 $-2^{\circ} \mathrm{C}$ 至 $10^{\circ} \mathrm{C}$, 年降水 量约 29-500 mm, 阿拉善高原的年降水量仅 50$150 \mathrm{~mm}$, 而额济纳旗仅有 $36 \mathrm{~mm}$ (裴浩等, 2000), 且蒸发量相对较大。内蒙古西部日照充足，大部分 地区的年日照时数都超过 $2,700 \mathrm{~h}$, 阿拉善高原西部 地区的年日照时数超过 $3,400 \mathrm{~h}$ 。该地区以温带荒漠 和温带草原为主, 典型植物群落包括克氏针茅 (Stipa krylovii)草原、短花针茅(S. breviflora)草原、 油蒿(Artemisia ordosica)灌从、藏锦鸡儿(Caragana tibetica) 灌丛、红砂 (Reaumuria songarica)和白刺 (Nitraria tangutorum) 灌从等。

\section{2 数据获取}

根据中国植被图和实际考察情况，分别于 2012-2015年的7-8月选择代表性植物群落样地 74 个进行调查(图1)。调查采用样方法, 群落类型通过 优势种进行确定(吴征镒, 1980)。样方的选取原则为 尽量选择围封或远离城镇公路、人类活动干扰少的 


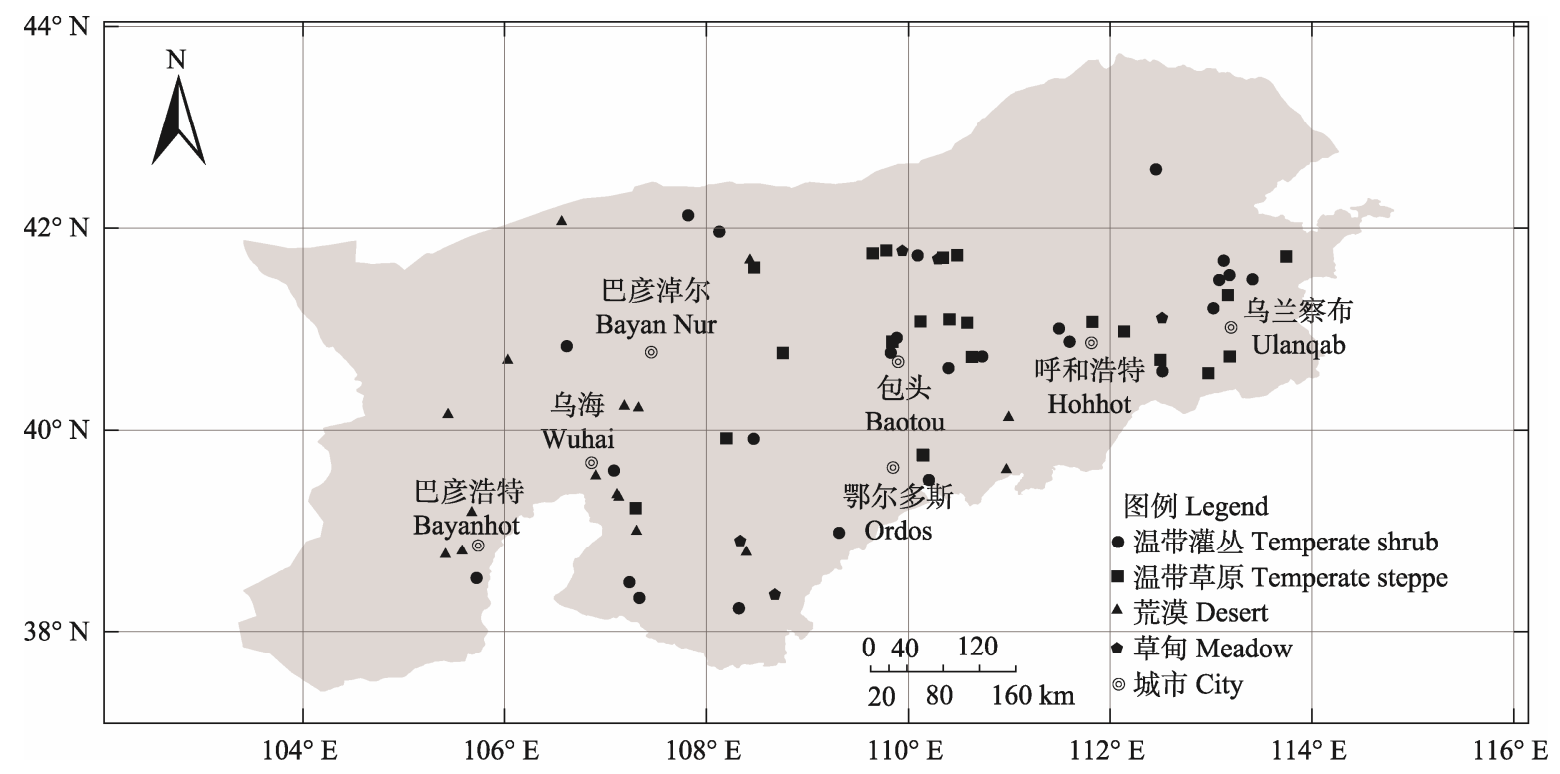

图1 内蒙古西部研究区样地分布图

Fig. 1 Distribution of sampling sites in western Inner Mongolia

开阔地, 面积均为 $10 \mathrm{~m} \times 10 \mathrm{~m}$ 。对于灌木样地, 在 样方4角设置 4 个面积为 $1 \mathrm{~m} \times 1 \mathrm{~m}$ 的草本样方。对灌 木和草本进行分层调查, 调查内容为灌木和草本的 种类、高度、盖度。对于草本样地, 在样方 4 角及中 间设置 5 个面积为 $1 \mathrm{~m} \times 1 \mathrm{~m}$ 的小样方, 记录每个小 样方中所有物种的种类、高度、盖度(方精云等, 2009), 最后统计每个物种在样地的出现次数以计 算频度。

各样地用土壤取样器采集土壤样品。采样深度 为 $1 \mathrm{~m}$, 按照0-10 $\mathrm{cm} 、 10-20 \mathrm{~cm} 、 20-30 \mathrm{~cm} 、 30-$ $50 \mathrm{~cm} 、 50-70 \mathrm{~cm} 、 70-100 \mathrm{~cm}$ 分为6层取样, 各层样 品装入封口聚乙烯塑料袋带回实验室。将样品自然 风干, 研磨过篮后, 采用重铬酸钾氧化-外加热法测 定有机碳含量(total organic carbon, TOC), 全氮 (total nitrogen, TN) 用凯氏定氮法测定, 全磷 (total phosphorus, TP)采用碱熔-钼锑抗比色法测定; 使用 $\mathrm{pH}$ 计测定 $\mathrm{pH}$ 值。

从WorldClim数据库(http://www.worldclim.org/) 获取月均温和逐月降水量数据, 空间分辨率为 $30^{\prime \prime}$ (相当于赤道地区 $1 \mathrm{~km}$ )。年均温(mean annual temperature, MAT, ${ }^{\circ} \mathrm{C}$ )、年平均降水量 (mean annual precipitation, MAP, mm)、潜在蒸散量 (potential evapotranspiration, PET, mm) (方精云等, 2009)、最 冷月均温(mean temperature of the coldest month,
$\left.\mathrm{MTCM},{ }^{\circ} \mathrm{C}\right)$ 根据月均温和逐月降水量数据计算 得到。

\section{3 数据处理}

群落的物种多样性是指群落中植物种类的丰 富程度, 而物种多样性( $\alpha$ 多样性)指标是度量物种 多样性高低及空间分布特征的数值指标。近年来对 植物群落物种多样性的研究采用的测度指数主要 包括物种丰富度指数、物种多样性指数及均匀度指 数, 其中, Patrick丰富度指数、Simpson指数、 Shannon-Wiener指数和Pielou均匀度指数在测度物 种多样性中较为常见, 与其他研究具有较大可比性 (汪殿蓓等, 2001)。本文也采用这4种多样性指数来 表征研究区植物群落的物种多样性。在计算过程中, 首先根据每个样方中各灌木、草本物种的高度、盖 度、频度计算每个物种的重要值 $\left(p_{\mathrm{i}}\right)$ (Zhang et al, 2006):

$p_{\mathrm{i}}=($ 相对高度 + 相对盖度 + 相对频度 $) / 3$ (1)

然后根据每个样方内各物种重要值计算群落 的多样性指数。

Patrick丰富度指数 $R=S$

Simpson指数 $\lambda=-\sum_{i=1}^{s} p_{\mathrm{i}}^{2}$

Shannon-Wiener指数 $H=-\sum_{i=1}^{s} p_{\mathrm{i}} \ln \left(p_{\mathrm{i}}\right)$ 
Pielou均匀度指数 $E=\frac{H^{\prime}}{\ln (S)}$

其中, $S$ 为每个样方内的物种数, $p_{\mathrm{i}}$ 为第 $\mathrm{i}$ 个物种的重 要值(马克平等, 1995)。

最后，通过Pearson相关分析确定不同环境因 子与群落物种多样性的关系, 采用多元回归分析确 定影响群落物种多样性的主导因子。数据的初步处 理利用Microsoft Excel 2007完成, 回归分析利用 SPSS 20.0完成，采用R 3.4.1绘制图形。

\section{2 结果}

\section{1 内蒙古西部自然植被的群落特征}

此次调查的植物群落可划分为4种植被型，即 温带灌从、温带草原、荒漠和草甸(表1)。内蒙古西 部具有丰富的灌木资源, 在此次调查中, 27 个灌丛 样地被划分为 14 个灌木群落。该地区的灌从性质差 异明显, 在大青山东段以森林气候下的次生灌丛为 主, 如虎榛子(Ostryopsis davidiana)灌丛和蒙古绣 线菊(Spiraea mongolica)灌从。在草原区则广泛分布 着旱生的落叶灌丛, 灌木呈斑块状分布在草原基质 上, 草本层以草原种类为主, 如典型草原区的小叶 锦鸡儿(Caragana microphylla)灌丛和荒漠草原区的 藏锦鸡儿灌丛。在荒漠草原和荒漠区的干旱山地上 则生长着特有的蒙古扁桃(Amygdalus mongolica)灌 丛, 而沙地柏(Juniperus sabina)灌丛、油蒿灌丛和西 伯利亚白刺(Nitraria sibirica)灌从等则在沙地、盐碱
地等隐域生境上广泛分布。温带草原调查了 10 个群 落类型共 25 个样地, 包括典型草原(克氏针茅草原)、 荒漠草原(小针茅(Stipa klemenzii)草原、短花针茅草 原等)、山地草原(羊茅(Festuca ovina)草原)及因放牧 干扰而蒿属植物占优势的蒿类草原(冷蒿(Artemisia frigida)草原)。该地区荒漠类型多样，西鄂尔多斯阿拉善荒漠为我国八大特有植物中心之一, 分布着 以古地中海子遗植物为建群种的荒漠植被, 如四合 木(Tetraena mongolica)荒漠、半日花(Helianthemum songaricum)荒漠和沙冬青(Ammopiptanthus mongolicus)荒漠(赵一之, 2006), 具有重要的保护价值。在 该地区的隐域生境上也分布着较大面积的草甸植 被, 此次调查到 3 个类型, 以芨芨草(Achnatherum splendens)草甸最为常见。

\section{2 内蒙古西部自然植被的物种多样性特征}

总体来说, 内蒙古西部自然植被的物种数较少, 物种多样性偏低, 群落结构较为简单。物种多样性 指数的变化趋势与物种数基本一致, 表现为物种数 越多, 多样性指数越高(图2)。温带草原和草甸的物 种相对丰富, 但草甸的物种丰富度指数的标准差和 变异系数都远大于草原, 这可能主要是因为草甸包 含了一个臺草-杂类草草甸样地, 其丰富度指数高 达26.20, 而剔除该样地后草甸的丰富度指数仅为 7.66 , 远低于草原。温带灌丛的物种多样性略低于 温带草原和草甸, 但其变异系数高于温带草原, 这 说明各灌木群落之间的物种多样性指数差异相对

表1 内蒙古西部植物群落类型

Table 1 Community types of western Inner Mongolia

\begin{tabular}{|c|c|c|}
\hline $\begin{array}{l}\text { 植被型 } \\
\text { Vegetation type }\end{array}$ & $\begin{array}{l}\text { 样地数 } \\
\text { Plot number }\end{array}$ & $\begin{array}{l}\text { 群落名称 } \\
\text { Community name }\end{array}$ \\
\hline $\begin{array}{l}\text { 温带灌从 } \\
\text { Temperate shrub }\end{array}$ & 27 & 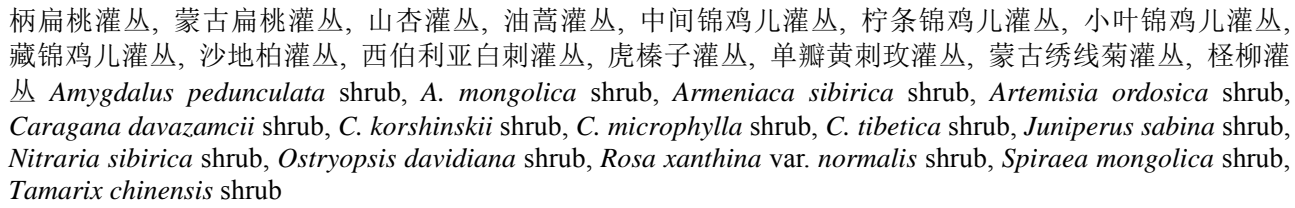 \\
\hline
\end{tabular}

温带草原 25 冷蒿草原, 白莲蒿草原, 无芒隐子草草原, 羊茅草原, 羊草草原, 短花针茅草原, 沙生针茅草原, 戈壁针茅 Temperate steppe 草原, 小针茅草原, 克氏针茅草原 Artemisia frigida steppe, A. sacrorum steppe, Cleistogenes songorica steppe, Festuca ovina steppe, Leymus chinensis steppe, Stipa breviflora steppe, S. glareosa steppe, S. gobica steppe, S. klemenzii steppe, S. krylovii steppe

荒漠 16 沙米+虫实+猪毛菜荒漠, 沙冬青荒漠, 籽蒿荒漠, 中亚紫苑木荒漠, 梭梭荒漠, 半日花荒漠, 盐爪爪荒漠, 驼线藜荒漠, 红砂荒漠, 几合木荒漠, 霸王荒漠 Agriophyllum squarrosum + Corispermum sp+ Salsola sp. desert, Ammopiptanthus mongolicus desert, Artemisia sphaerocephala desert, Asterothamnus centraliasiaticus desert, Haloxylon ammodendron desert, Helianthemum songaricum desert, Kalidium foliatum desert, Krascheninnikovia ceratoides desert, Reaumuria songarica desert, Tetraena mongolica desert, Zygophyllum xanthoxylon desert

草甸 Meadow 6 芨芨草草甸, 拂子茅草甸, 薹草-杂类草草甸 Achnatherum splendens meadow, Calamagrostis epigeios meadow, Carex spp. -forb meadow 

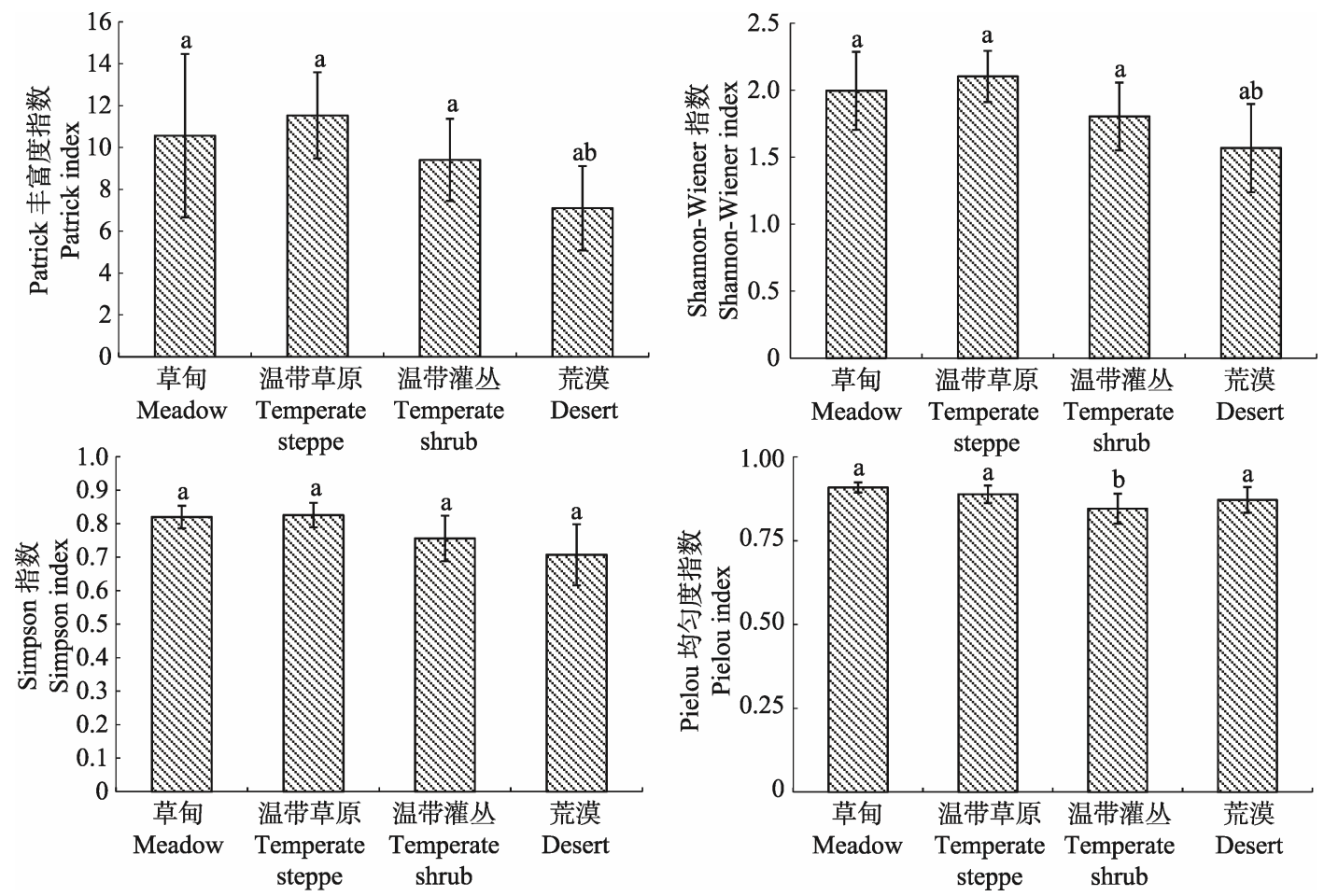

图2 内蒙古西部不同群落类型多样性指数对比

Fig. 2 Biodiversity indices of different community types in western Inner Mongolia

于温带草原来说较大。荒漠的物种多样性最低, 其 Partrick丰富度指数 $(P=0.003)$ 和Shannon-Wiener指 数 $(P=0.001)$ 与其他 3 种植被型均差异显著, 物种丰 富度指数均值仅为 7.11 , 且其变异系数较大, 最大 值出现在沙冬青荒漠(Patrick丰富度指数12.667)。而 物种数最少且多样性指数最小的沙米(Agriophyllum squarrosum) + 虫实(Corispermum sp.) + 猪毛菜 (Salsola sp.)荒漠, 其Patrick丰富度指数仅 2.60 。各植 被型的Pielou均匀度指数差异均不显著 $(P=0.126)$ 。

\section{3 影响群落物种多样性的因素}

\subsection{1 气候因子与群落物种多样性指数的关系}

结果表明, 年均温(MAT)、年降水量(MAP)、最 冷月均温(MTCM)和潜在蒸散量(PET) 4 个气候因子 对群落的物种多样性均有影响(表2)。Patrick丰富度 指数与MAT $(P<0.01) 、$ MTCM $(P<0.01)$ 和PET $(P<0.01)$ 均呈极显著的负相关关系, 与MAP呈极 显著的正相关关系 $(P<0.01)$ 。Simpson指数与PET $(P<0.01)$ 呈极显著的负相关关系，与MAT $(P<0.05)$ 呈显著的负相关关系, 受MAP和MTCM影响不明 显。Shannon-Wiener指数与Patrick丰富度指数相似, 均与MAT $(P<0.01) 、$ MTCM $(P<0.01)$ 和PET $(P<$
0.01)呈极显著的负相关关系, 而与 MAP呈显著的 正相关关系 $(P<0.05)$ 。Pielou均匀度指数与各气候 因子之间的关系均不显著(表2)。

\subsection{2 土壤因子与群落物种多样性的关系}

Pearson相关分析显示, 土壤化学性质指标中, 土壤 $\mathrm{pH}$ 值和有机碳含量对群落的物种多样性影响 较大 (表 3)。Patrick丰富度指数 $(P<0.01)$ 、 Shannon-Wiener指数 $(P<0.01)$ 和Simpson指数 $(P<$ $0.05)$ 均与土壤 $\mathrm{pH}$ 值呈显著的负相关关系。 4 个多样 性指数均与有机碳含量呈极显著的正相关关系 $(P<$ $0.01)$ 。Patrick丰富度指数 $(P<0.05)$ 、Shannon-Wiener 指数 $(P<0.05)$ 及 Pielou均匀度指数 $(P<0.01)$ 均与土 壤全氮呈显著的正相关关系, 其中对Pielou均匀度 指数的影响极显著。土壤全磷对 4 个多样性指数的 影响均不显著。

\subsection{3 影响群落物种多样性的主导因子}

通过多元逐步回归分析影响各个多样性指数 的主导因子, 结果如表4所示。各环境因子中, 潜在 蒸散量和土壤有机碳含量被引入到解释Patrick丰富 度指数的方程中, 且潜在蒸散量作为最重要的影响 因子解释了丰富度指数的 $35.8 \%$ 。而Simpson指数主 
表2 内蒙古西部植物群落物种多样性指数与气候因子的Pearson相关性分析结果

Table 2 Pearson correlation analysis between species diversity indices and climatic factors of plant communities in western Inner Mongolia

\begin{tabular}{llll}
\hline $\begin{array}{l}\text { 多样性指数 } \\
\text { Diversity index }\end{array}$ & $\begin{array}{l}\text { 年均温 Mean annual } \\
\text { temperature }\end{array}$ & $\begin{array}{l}\text { 年降水 Mean annual } \\
\text { precipitation }\end{array}$ & $\begin{array}{l}\text { 最冷月均温 Mean tempera- 潜在蒸散量 Potential } \\
\text { ture of the coldest month } \\
\text { evapotranspiration }\end{array}$ \\
\hline Patrick丰富度指数 Patrick index & $-0.541^{* *}$ & $0.367^{* *}$ & $-0.446^{* *}$ \\
Simpson指数 Simpson index & $-0.294^{*}$ & 0.139 & -0.212 \\
Shannon-Wiener指数 Shannon-Wiener index & $-0.418^{* *}$ & $0.253^{*}$ & $-0.326^{* *}$ \\
Pielou均匀度指数 Pielou index & -0.067 & -0.042 & -0.003 \\
\hline
\end{tabular}

*在 0.05 水平(双侧)上显著相关; $* *$ 在 0.01 水平(双侧)上显著相关。

* significant correlation at 0.05 level (2-tails); ** significant correlation at 0.01 level (2-tails).

表3 内蒙古西部植物群落物种多样性指数与土壤化学性质的Pearson相关性分析结果

Table 3 Pearson correlation analysis between species diversity indices and soil chemical properties of plant communities in western Inner Mongolia

\begin{tabular}{lllll}
\hline 多样性指数 Diversity index & $\mathrm{pH}$ & 有机碳 Total organic carbon & 全氮 Total nitrogen & 全磷 Total phosphorus \\
\hline Patrick丰富度指数 Patrick index & $-0.511^{* *}$ & $0.509^{* *}$ & $0.307^{*}$ & 0.171 \\
Simpson指数 Simpson index & $-0.286^{*}$ & $0.388^{* *}$ & 0.226 & 0.096 \\
Shannon-Wiener指数 Shannon-Wiener index & $-0.388^{* *}$ & $0.462^{* *}$ & $0.271^{*}$ & -0.151 \\
Pielou均匀度指数 Pielou index & -0.119 & $0.330^{* *}$ & $0.326^{* *}$ & 0.133 \\
\hline
\end{tabular}

*在 0.05 水平(双侧)上显著相关; **在 0.01 水平(双侧)上显著相关。

* significant correlation at 0.05 level (2-tails); ** significant correlation at 0.01 level (2-tails).

表4 多元逐步回归分析结果

Table 4 Results of stepwise regression analysis

\begin{tabular}{|c|c|c|c|}
\hline $\begin{array}{l}\text { 因变量 } \\
\text { Dependent variable }\end{array}$ & $\begin{array}{l}\text { 引入变量 } \\
\text { Variables entered }\end{array}$ & $\begin{array}{l}\text { 调整 } R^{2} \\
\text { Adjusted } R^{2}\end{array}$ & $\begin{array}{l}P \text { 值 } \\
P \text { value }\end{array}$ \\
\hline \multirow{2}{*}{$\begin{array}{l}\text { Patrick丰富度指数 } \\
\text { Patrick index }\end{array}$} & PET & 0.358 & 0.000 \\
\hline & TOC & 0.415 & 0.010 \\
\hline Simpson指数 Simpson index & TOC & 0.122 & 0.003 \\
\hline \multirow{2}{*}{$\begin{array}{l}\text { Shannon-Wiener指数 } \\
\text { Shannon-Wiener index }\end{array}$} & PET & 0.196 & 0.008 \\
\hline & TOC & 0.259 & 0.015 \\
\hline $\begin{array}{l}\text { Pielou均匀度指数 Pielou } \\
\text { index }\end{array}$ & $\mathrm{TN}$ & 0.108 & 0.005 \\
\hline
\end{tabular}

PET: 潜在蒸散量; TOC: 有机碳; TN: 全氮。

PET, Potential evapotranspiration; TOC, Total organic carbon; TN, Total nitrogen.

要受到土壤有机碳含量的影响, 解释率为 $12.2 \%$ 。 Shannon-Wiener指数与丰富度指数类似, 最重要的 两个影响因子也是潜在蒸散量和土壤有机碳含量, 其中, 潜在蒸散量解释了 Shannon-Wiener指数的 $19.6 \%$ 。潜在蒸散量和土壤有机碳含量是对物种多 样性影响最大的因子。而对均匀度指数影响最大的 环境因子是土壤全氮含量, 其解释率为 $10.8 \%$ 。

\section{3 讨论}

\section{1 不同植被类型的物种多样性}

本研究调查的所有群落中, 温带草原群落的物 种多样性最高(Patrick指数 11.37 , Simpson指数 0.83 ,
Shannon-Wiener指数2.09), 这与已有温带草原多样 性的研究结果相近, 如鄂尔多斯高原典型草原 Patrick丰富度指数为 11.13 , Simpson指数为 0.79 , Shannon-Wiener指数为 1.99 (黄永梅和张明理, 2006)。本研究区内草甸的物种多样性与温带草原群 落的物种多样性基本一致, 但剔除其中一个丰富度 指数(Patrick指数为 26.20)高的薹草-杂类草草甸样 地后, 草甸群落的丰富度指数变得较低(均值为 7.66)。这可能主要是因为此次调查的草甸群落以夰 芨草草甸为主, 属于丛生禾草盐生草甸 (吴征镒, 1980), 为温带干旱、半干旱地区所特有, 生境相对 较干旱, 土壤盐碱化明显, 植物种类组成比较贵乏, 群落的多样性也相对较低。结合已有研究表明半干 旱区盐生草甸均具有相对较低的物种丰富度, 如宋 创业等(2008)在浑善达克沙地的研究表明，丘间低 地及淖尔边缘的拂子茅(Calamagrostis epigejos)群 落、芦苇(Phragmites communis)群落、金戴戴 (Halerpestes ruthenica) 群落Patrick丰富度指数均低 于10, 而左小安等(2007)在科尔沁沙地的研究结果 表明, 湿草甸和干草甸的Patrick丰富度指数平均值 也仅为 11.5 和 14 。本研究区灌丛以草原化灌丛、沙 地灌丛为主，均为中生-旱生种(杨明博等，2005), 所以灌从的多样性也低于森林区的暖温带灌从(谢 
晋阳和陈灵芝，1997; 张书理，2007; 周志宇等, 2009)。荒漠是内蒙古西部的典型群落类型, 该地区 约有一半的面积被荒漠覆盖, 荒漠的物种多样性低 于其他各类群落。总体而言, 除温带草原群落外, 研究区各群落类型的多样性均偏低。

\section{2 影响物种多样性的因素}

植物群落物种多样性的主要影响因素有地形 因子、气候因子、土壤理化性质、人类活动等(Sander \& Wardell-Johnson, 2011), 本文综合分析了气候因子 和土壤理化性质对该地区植物群落物种多样性的 影响。

\subsection{1 气候因子}

内蒙古西部处于干旱、半干旱区，一般认为水 热因子是影响该区域植物群落物种多样性的主要 因素，如锡林河流域(刘先华等，1998; 白永飞等， 2000)、内蒙古荒漠草原(Zhang et al, 2014b; 孙小丽 等, 2015)、内蒙古草原(Zhang et al, 2014a)的研究表 明物种丰富度和多样性均与年降水量呈正相关, 而 与年均温呈负相关关系。在本研究中, Patrick丰富度 指数、Simpson指数和Shannon-Wiener指数均与年均 温呈显著的负相关关系, 而Patrick丰富度指数和 Simpson指数与年降水量呈显著的正相关关系, 这 与已有研究结果基本一致, 说明水热因子对该区域 植物群落的物种多样性存在较大的影响。此外, 冬 季寒冷会影响多年生植物的生活史策略, 从而影响 群落的物种多样性(Zhang et al, 2016), 因此, 最冷 月均温对群落的物种多样性也具有重要意义。一般 来说, 冬季寒冷使物种多样性降低。Zhang等(2014b) 的研究也表明, 最冷月均温对灌木-半灌木群落的 多样性具有显著的影响。本研究中Patrick丰富度指 数和Shannon-Wiener指数均与最冷月均温具有显著 的负相关关系。年均温和最冷月均温对物种多样性 的影响机制还需要进一步探索。

在北美、非洲以及欧亚草原的许多研究表明, 降水是群落物种多样性最主要的影响因子(Bai et al, 2008; Collins et al, 2012; Volder et al, 2013)。而在本 研究中, 基于年均温和年降水量计算的潜在蒸散量 对群落的物种多样性影响显著, 多元逐步回归结果 也表明, 潜在蒸散量是内蒙古西部群落物种多样性 的主导因素中唯一的气候因子(表4)。潜在蒸散量作 为综合热量和水分两个最重要的生态因子的参数, 对于植被的分布和群落的组成具有重要意义(van
Bavel, 1966; 张新时， 1989; 周广胜和张新时, 1996)。在非洲南部的研究表明, 与温度相比, 潜在 蒸散量可能更适合用于反映热量或能量对植被的 影响(O’Brien, 1993)。代爽等(2013)对内蒙古中西部 灌木群落的研究发现, 物种丰富度的地理格局受水 分和能量共同限制的水分能量动态假说也能较好 地解释本研究区灌木群落多样性的地理格局, 而潜 在蒸散量正是该假说的主要参数之一。孙小丽等 (2015)对内蒙古荒漠草原的研究也发现, 反映水分 和温度综合作用的干燥指数在对群落物种多样性 的作用中占主导地位。本研究区内潜在蒸散量最低 的薹草-杂类草草甸群落中, Patrick丰富度指数高达 26.20, 而潜在蒸散量最高的梭梭 (Haloxylon ammodendron) 荒漠群落, 其Patrick丰富度指数仅为 3.67 。本研究中, Patrick丰富度指数、Shannon-Wiener 指数和Simpson指数均与潜在蒸散量呈极显著的负 相关关系。所以, 未来的群落物种多样性的影响因 素研究中, 应更重视潜在蒸散量的影响。

\subsection{2 土壤化学性质}

土壤理化性质会在局域尺度上影响群落的物 种多样性, 本文分析了土壤化学性质对群落物种多 样性的影响。多元回归分析结果显示, 土壤有机碳 含量是群落物种多样性的主导因子之一, 而全氮则 是Pielou均匀度指数的主导因子(表4)。

土壤有机碳含量及其动态平衡是反映土壤质 量的一个重要指标, 直接影响着土壤肥力, 从而影 响植物营养的生物有效性(Doran et al, 1998)。王艳 芬等(1998)的研究发现, 土壤有机碳含量和组成不 仅表征土壤有机质的水平, 而且能够说明营养元素 $\mathrm{N} 、 \mathrm{P}$ 等的可利用状态。因此, 高的有机碳含量与较 高的土壤肥力紧密相关, 从而能够支持更高的物种 多样性。在阿尔金山自然保护区的研究表明植物群 落的多样性指数与土壤总碳、土壤有机碳呈显著正 相关(沙威等, 2016)。白永飞等(2000)对锡林河流域 草原群落多样性的研究也表明, 在样带梯度上, 物 种丰富度、多样性指数与土壤有机碳及全氮含量呈 正相关。本研究也发现在内蒙古西部的自然植物群 落中, 物种多样性与土壤有机碳含量具有显著的正 相关关系。土壤有机碳含量较高的臺草-杂类草草 甸、白莲蒿(Artemisia sacrorum)草原等具有较高的 物种多样性, 而土壤有机碳含量最低的柽柳 (Tamarix chinensis)灌从, 其Patrick丰富度指数仅 
为 4.00 。

氮的可利用性是陆地生态系统的主要限制因 素之一, 影响着生态系统的物种多样性(Vitousek \& Howarth, 1991)。目前广泛开展的氮添加实验结果表 明, 氮的增加会使群落的物种多样性降低。但 Suding等(2004)的研究发现, 在氮限制的地区增加 氮素会使群落的物种多样性增加。内蒙古西部地区 属于氮限制地区(Bai et al, 2010), 在不添加外源氮 素的情况下, 土壤全氮含量较高的群落, 氮限制的 程度相对较轻, 可维持较高的物种多样性。而较高 的氮素也使植物对氮素的竞争减弱, 这也可以解释 为何在研究区内全氮含量成为Pielou均匀度指数的 主导因子。研究区中土壤全氮含量较低的柽柳灌 丛、红砂荒漠及四合木荒漠的物种多样性均较低, Patrick丰富度指数均低于 8 , Pielou均匀度指数也较 其他群落低。王蒙等(2015)对巴丹吉林沙漠南缘自 然植被的研究结果也显示, 均匀度指数与土壤全氮 含量显著相关, 而丰富度指数则主要受有机质含量 影响。有研究表明, 全球氮沉降水平预计在未来 25 年内会加倍(Neff et al, 2002), 在这样的背景下, 内 蒙古西部自然植被物种多样性将如何变化也值得 进一步探讨。

群落的物种多样性是多种环境因子共同作用 的结果，除了前文所述气候条件和土壤理化性质外, 地形因素和人类活动干扰的影响也不容忽视, 未来 对内蒙古西部自然植被物种多样性的影响因素的 研究还有待进一步加强。

\section{参考文献}

Bai YF, Li LH, Wang QB, Zhang LX, Zhang Y, Chen ZZ (2000) Changes in plant species diversity and productivity along gradients of precipitation and elevation in the Xilin River Basin, Inner Mongolia. Acta Phytoecologica Sinica, 24, 667-673. (in Chinese with English abstract) [白永飞, 李凌浩, 王其兵, 张丽霞, 张炎, 陈佐忠 (2000) 锡林河 流域草原群落植物多样性和初级生产力沿水热梯度变化 的样带研究. 植物生态学报, 24, 667-673.]

Bai YF, Wu JG, Chritopher MC, Shahid N, Pan QM, Huang JH, Zhang LX, Han XG (2010) Tradeoffs and thresholds in the effects of nitrogen addition on biodiversity and ecosystem functioning: evidence from Inner Mongolia Grasslands. Global Change Biology, 16, 358-372.

Bai YF, Wu JG, Xing Q, Pan QM, Huang JH, Yang DL, Han XG (2008) Primary production and rain use efficiency across a precipitation gradient on the Mongolia Plateau.
Ecology, 89, 2140-2153.

Bellard C, Bertelsmeier C, Leadley P, Thuiller W, Courchamp $F$ (2012) Impact of climate change on the future of biodiversity. Ecology Letters, 15, 356-377.

Brown JH, Lomolino MV (1998) Biogeograph, 2nd edn. Sinauer Associates, Sunderland, Massachusetts.

Collins SL, Koerner SE, Plaut JA, Okie JG, Brese D, Calabrese LB, Carvajal A, Evansen RJ, Nonaka E (2012) Stability of tallgrass prairie during a 19 -year increase in growing season precipitation. Functional Ecology, 26, 1450-1459.

Dai S, Wang XP, Liu C, Wu X, Li QY, Wang M (2013) Relationship between shrub species richness and climate across central Inner Mongolia, China. Acta Scientiarum Naturalium Universitatis Pekinensis, 49, 689-698. (in Chinese with English abstract) [代爽, 王襄平, 刘超, 武㜆, 李巧燕, 王 敏 (2013) 内蒙古灌木群落物种丰富度与气候的关系. 北京大学学报(自然科学版), 49, 689-698.]

Doran JW, Elliott ET, Paustian K (1998) Soil microbial activity, nitrogen cycling, and long-term changes in organic carbon pools as related to fallow tillage management. Soil \& Tillage Research, 49, 3-18.

Fang JY, Wang XP, Shen ZH, Tang ZY, He JS, Yu D, Jiang Y, Wang ZH, Zheng CY, Zhu JL, Guo ZD (2009) Methods and protocols for plant community inventory. Biodiversity Science, 17, 533-548. (in Chinese with English abstract) [方精 云, 王襄平, 沈泽吴, 唐志尧, 贺金生, 于丹, 江源, 王志 恒, 郑成洋, 朱江玲, 郭兆迪 (2009) 植物群落清查的主 要内容、方法和技术规范. 生物多样性, 17, 533-548.]

Feng JM (2008) Spatial patterns of species diversity of seed plants in China and their climatic explanation. Biodiversity Science, 16, 470-476. (in Chinese with English abstract) [冯 建孟 (2008) 中国种子植物物种多样性的大尺度分布格 局及其气候解释. 生物多样性, 16, 470-476.]

Feng XW, Wang Y, Wu LP (2003) Integrated ecological environment evaluation in west region of Inner Mongolia. Journal of Desert Research, 3, 322-327. (in Chinese with English abstract) [冯学武, 王式, 吴丽萍 (2003) 内蒙古西部 生态环境综合评价研究. 中国沙漠, 3, 322-327.]

He JS, Chen WL (1997) A review of gradient changes in species diversity of land plant communities. Acta Ecologica Sinica, 17, 91-99. (in Chinese with English abstract) [贺金 生, 陈伟烈 (1997) 陆地植物群落物种多样性的梯度变 化特征. 生态学报, 17, 91-99.]

Huang YM, Zhang ML (2006) Temporal and spatial changes of plant community diversity on the Ordos Plateau. Biodiversity Science, 14, 13-20. (in Chinese with English abstract) [黄永梅, 张明理 (2006) 鄂尔多斯高原植物群落多样性 时空变化特点. 生物多样性, 14, 13-20.]

Liu XH, Li LH, Chen ZZ (1998) Characteristics of vegetation diversity in the Xilin River Basin and their responses to climatic factors. Acta Phytoecologica Sinica, 22, 466-472. (in Chinese with English abstract) [刘先华, 李凌浩, 陈佐忠 (1998) 内蒙古锡林河流域植被多样性特点及其与气候因 
子的关系. 植物生态学报, 22, 466-472.]

Loreau M, Naeem S, Inchausti P, Bengtsson J, Grime JP, Hector A, Hooper DU, Huston MA, Raffaelli D, Schmid B, Tilman D, Wardle DA (2001) Biodiversity and ecosystem functioning: current knowledge and future challenges. Science, 294, 804-808.

Ma B, Zhou ZY, Zhang LL, Gao WX, Chen SK, Zhang BL (2008) The spatial distribution characteristics of plant diversity in Alex Left Banner. Acta Ecologica Sinica, 28, 6099-6106. (in Chinese with English abstract) [马斌, 周志 宇, 张莉丽, 高文星, 陈善科, 张宝林 (2008) 阿拉善左 旗植物物种多样性空间分布特征。生态学报, 28 , 6099-6106.]

Ma KP, Huang JH, Yu SL, Chen LZ (1995) Plant community diversity in Dongling Mountain, Beijing, China. II. Species richness, evenness and species diversities. Acta Ecologica Sinica, 15, 268-277. (in Chinese with English abstract) [马 克平, 黄建辉, 于顺利, 陈灵芝 (1995) 北京东灵山地区 植物群落多样性的研究. II. 丰富度、均匀度和物种多样 性指数. 生态学报, 15, 268-277.]

Neff JC, Townsend AR, Gleixner G, Lehman SJ, Turnbull J, Bowman WD (2002) Variable effects of nitrogen additions on the stability and turnover of organic carbon. Nature, 419, 915-917.

O'Brien EM (1993) Climatic gradients in woody plant species richness: towards an explanation based on an analysis of southern Africa's woody flora. Journal of Biogeography, 20, 181-198.

Pei H, Ao YH, Li YP, Liu ZL, Zhu ZY, Wang W, Liang CZ (2000) The research on the climate division of Alashan League, Inner Mongolia. Journal of Arid Land Resources and Environment, 14(3), 46-55. (in Chinese with English abstract) [裴浩, 敖艳红, 李云鹏, 刘钟龄, 朱宗元, 王炜, 梁存柱 (2000) 内蒙古阿拉善地区气候区划研究. 干旱 区资源与环境, 14(3), 46-55.]

Phillips OL, Vargas PN, Monteagudo AL, Cruz AP, Zans MEC, Sánchez WG, Yli-Halla M, Rose S (2003) Habitat association among Amazonian tree species: a landscape-scale approach. Journal of Ecology, 91, 757-775.

Qian H, Klinka K, Kajahara GJ (1998) Longitudinal patterns of plant diversity in the North American boreal forest. Plant Ecology, 138, 161-178.

Sander J, Wardell-Johnson G (2011) Impacts of soil fertility on species and phylogenetic turnover in the high-rainfall zone of the Southwest Australian global biodiversity hotspot. Plant Soil, 345, 103-124.

Sha W, Dong SK, Liu SL, Liu QR, Shi JB, Li XW, Su XK, Wu Y (2016) Spatial patterns of plant community biomass and species diversity in Aerjin Mountain Nature Reserve and their influencing factors. Chinese Journal of Ecology, 35, 330-337. (in Chinese with English abstract) [沙威, 董世鬼, 刘世梁，刘全儒，石建斌，李晓文，苏旭坤，吴娱 (2016) 阿尔金山自然保护区植物群落生物量和物种多样性的空 间格局及其影响因素. 生态学杂志, 35, 330-337.]

Song CY, Guo K, Liu GH (2008) Relationships between plant community's species diversity and soil factors on Otingdag sandy land. Chinese Journal of Ecology, 27, 8-13. (in Chinese with English abstract) [宋创业, 郭柯, 刘高焕 (2008) 浑善达克沙地植物群落物种多样性与土壤因子的关系. 生态学杂志, 27, 8-13.]

Suding KN, Gross KL, Houseman GR (2004) Alternative states and positive feedbacks in restoration ecology. Trends in Ecology \& Evolution, 19, 46-53.

Sun XL, Kang S, Zhang Q, Chang CM, Ma WJ, Niu JM (2015) Relationship between species diversity, productivity, climatic factors and soil nutrients in the desert steppe. Acta Prataculturae Sinica, 24(12), 10-19. (in Chinese with English abstract) [孙小丽, 康萨如拉, 张庆, 常昌明, 马文静, 牛建明 (2015) 荒漠草原物种多样性、生产力与气候因子 和土壤养分之间关系的研究. 草业学报, 24(12), 10-19.]

Tang ZY, Fang JY (2004) A review on the elevational patterns of plant species diversity. Biodiversity Science, 12, 20-28. (in Chinese with English abstract) [唐志尧, 方精云 (2004) 植物物种多样性的垂直分布格局. 生物多样性, 12 , 20-28.]

van Bavel CHM (1966) Potential evaporation: the combination concept and its experimental verification. Water Resources Research, 2, 455-467.

Vitousek PM, Howarth RW (1991) Nitrogen limitation on land and in the sea: how can it occur? Biogeochemistry, 13, 87-115.

Volder A, Briske DD, Tjoelker MG (2013) Climate warming and precipitation redistribution modify tree-grass interactions and tree species establishment in a warm-temperate savanna. Global Change Biology, 19, 843-857.

Wang CL, Guo QS, Tan DY, Shi ZM, Ma C (2005) Haloxylon ammodendron community patterns in different habitats along southeastern edge of Zhunger Basin. Chinese Journal of Applied Ecology, 16, 1224-1229. (in Chinese with English abstract) [王春玲, 郭泉水, 谭德远, 史作民, 马超 (2005) 准噶尔盆地东南缘不同生境条件下梭梭群落结构 特征研究. 应用生态学报, 16, 1224-1229.]

Wang CT, Wang QJ, Long RJ, Jing ZC, Shi HL (2004) Changes in plant species diversity and productivity along an elevation gradient in an alpine meadow. Acta Phytoecologica Sinica, 28, 240-245. (in Chinese with English abstract) [王长庭, 王启基, 龙瑞军, 景增春, 史惠兰 (2004) 高寒草甸群落植物多样性和初级生产力沿海拔梯度变化 的研究. 植物生态学报, 28, 240-245.]

Wang DB, Ji SY, Chen FP (2001) A review on the species diversity of plant community. Chinese Journal of Ecology, 20(4), 55-60. (in Chinese with English abstract) [汪殿蓓, 暨淑仪, 陈飞鹏 (2001) 植物群落物种多样性研究综述. 生态学杂志, 20(4), 55-60.]

Wang M, Dong ZB, Luo WY, Lu JF, Li JY, Cui XJ, Zhang Y (2015) Species diversity of vegetation and its relationship with soil characteristics in the southern marginal zone of the Badain Jaran Desert. Acta Botanica Boreali-Occidentalia Sinica, 35, 379-388. (in Chinese with English abstract) [王 蒙, 董治宝, 罗万银, 逯军锋, 李继彦, 崔徐甲, 张玉 
(2015) 巴丹吉林沙漠南缘植被物种多样性及其与土壤特 性的关系. 西北植物学报, 35, 379-388.]

Wang YF, Chen ZZ, Tieszen LT (1998) Distribution of soil organic carbon in the major grasslands of Xilinguole, Inner Mongolia, China. Acta Phytoecologica Sinica, 22, 66-72. (in Chinese with English abstract) [王艳芬, 陈佐忠, Tieszen LT (1998) 人类活动对锡林郭勒地区主要草原土壤 有机碳分布的影响. 植物生态学报, 22, 66-72.]

Wu ZY (1980) Vegetation of China. Science Press, Beijing. (in Chinese) [吴征镒 (1980) 中国植被. 科学出版社, 北京.]

Xie JY, Chen LZ (1997) The studies of some aspects of biodiversity on scrubs in the warm temperate zone in China. Acta Phytoecologica Sinica, 21, 197-207. (in Chinese with English abstract) [谢晋阳, 陈灵芝 (1997) 中国暖温带若干灌 丛群落多样性问题的研究. 植物生态学报, 21, 197-207.]

Xu YJ, Chen YN, Li WH, Fu AH, Ma XD, Gui DW, Chen YP (2010) Distribution pattern and environmental interpretation of plant species diversity in the mountainous region of Ili River Valley, Xinjiang, China. Chinese Journal of Plant Ecology, 34, 1142-1154. (in Chinese with English abstract) [徐远杰, 陈亚宁, 李卫红, 付爱红, 马晓东, 桂东伟, 陈 亚鹏 (2010) 伊犁河谷山地植物群落物种多样性分布格 局及环境解释. 植物生态学报, 34, 1142-1154.]

Yang MB, Yang J, Yang JY (2005) Physiological and biochemical analysis of the leaves of seven species of Caragana. Acta Botanica Boreali-Occidentalia Sinica, 25, 2272-2276. (in Chinese with English abstract) [杨明博, 杨 劼, 杨九艳 (2005) 锦鸡儿属7种植物叶的生理生化分析. 西北植物学报, 25, 2272-2276.]

Zhang JN, Lai X, Li G, Zhao JN, Zhang YS, Yang DL (2010) Response of plant diversity and soil nutrient condition to grazing disturbance in Stipa baicalensis Roshev grassland. Acta Agrestia Sinica, 18, 177-182. (in Chinese with English abstract) [张静妮, 赖欣, 李刚, 赵建宁, 张永生, 杨殿林 (2010) 贝加尔针茅草原植物多样性及土壤养分对放牧干 扰的响应. 草地学报, 18, 177-182.]

Zhang Q, Hou XY, Li YH, Niu JM, Zhou YL, Ding Y, Zhao LQ, Li X, Ma WJ, Kang S (2014a) Alpha, beta and gamma diversity differ in response to precipitation in the Inner Mongolia grassland. PLoS ONE, 9, e93518.

Zhang Q, Wu JG, Buyantuev A, Niu JM, Zhou YL, Ding Y, Kang S, Ma W (2014b) Plant species diversity is correlated with climatic factors differently at the community and the functional group levels: a case study of desert steppe in Inner Mongolia, China. Plant Biosystems, 150(1), 121-123.

Zhang SL (2007) Study on Plants Diversity and Conservation in Saihanwula Nature Reserve, Inner Mongolia. PhD dissertation, Beijing Forestry University, Beijing. (in Chinese with English abstract) [张书理 (2007) 内蒙古赛罕乌拉自然保 护区植物多样性及其保护研究. 博士学位论文, 北京林 业大学, 北京.]

Zhang XP, Wang MB, She B, Xiao Y (2006) Quantitative classification and ordination of forest communities in Pangquangou National Nature Reserve. Acta Ecologica
Sinica, 26, 754-761.

Zhang XS (1989) The potential evapotranspriration (PE) index for vegetation and vegetation-climatic classification (1) - an introduction of main methods and PEP program. Acta Phytoecologica et Geobotanica Sinica, 13, 1-9. (in Chinese with English abstract) [张新时 (1989) 植被的PE (可能蒸散)指 标与植被-气候分类 (一) 一几种主要方法与PEP程序介 绍. 植物生态学与地植物学学报, 13, 1-9.]

Zhao YZ (2006) Vascular Plants of Plateau Ordos. Inner Mongolia University Press, Hohhot. (in Chinese) [ 赵一之 (2006) 鄂尔多斯高原维管植物. 内蒙古大学出版社, 呼 和浩特.]

Zheng JG, Wu GX, He MZ, Li XR, Gan HJ (2009) Correlation between plant diversity and soil properties in Alax Desert. Journal of Arid Land Resources and Environment, 23, 151-155. (in Chinese with English abstract) [郑敬刚, 吴国 秃, 何明珠, 李新荣, 甘红军 (2009) 阿拉善荒漠区植物 多样性与土壤理化性质相关性研究. 干旱区资源与环境, 23, 151-155.]

Zheng JK, Wei TX, Zheng LK, Dalin Z, Chen ZF, Zhao J, Zhu WD, Sun H (2009) Effects of landforms on $\alpha$ biodiversity in slope scale. Ecology and Environmental Sciences, 18, 2254-2259. (in Chinese with English abstract) [郑江坤, 魏 天兴, 郑路坤, 大林直, 陈致富, 赵健, 朱文德, 孙慧 (2009) 坡面尺度上地貌对 $\alpha$ 生物多样性的影响. 生态环 境学报, 18, 2254-2259.]

Zhou GS, Zhang XS (1996) Study on Chinese climate-vegetation relationship. Acta Phytoecologica Sinica, 20, 113-119. (in Chinese with English abstract) [周广胜, 张新时 (1996) 中国气候-植被关系初探. 植物生态学报, 20, 113-119.]

Zhou ZY, Yan SY, Qin Y, Zou LN (2009) The characters of shrubby diversity of Alax arid desert region. Journal of Arid Land Resources and Environment, 23, 146-150. (in Chinese with English abstract) [周志宇, 颜淑云, 秦或, 邹丽娜 (2009) 阿拉善干旱荒漠区灌木多样性的特点. 干旱区资 源与环境, 23, 146-150.]

Zhu Y, Kang MY, Liu QR, Su Y, Jiang Y, He KJ, Xu GC, Wang GR, Tao Y, Zhu HF (2007) Relationship between biodiversity and aboveground biomass in alpine meadow on Mt. Helan, China. Chinese Journal of Applied and Environmental Biology, 13, 771-776. (in Chinese with English abstract) [朱源，康慕谊，刘全儒，苏云，江源，和克俭， 徐广才, 王耿锐, 陶岩, 朱恒峰 (2007) 贺兰山高山草甸 生物多样性和地上生物量的关系. 应用与环境生物学报, 13, 771-776.]

Zuo XA, Zhao XY, Zhao HL, Li YQ, Guo YR, Zhao YP (2007) Changes of species diversity and productivity in relation to soil properties in sandy grassland in Horqin sand land. Environmental Science, 28, 945-951. (in Chinese with English abstract) [左小安, 赵学勇, 赵哈林, 李玉强, 郭轶 瑞, 赵玉萍 (2007) 科尔沁沙质草地群落物种多样性、生 产力与土壤特性的关系. 环境科学, 28, 945-951.]

(责任编委: 白永飞 责任编辑: 黄祥忠) 